\title{
Disciplining exporting state trading enterprises under economies of scale and oligopoly
}

\author{
Margherita Scoppola \\ University of Macerata, Italy
}

Received June 2006; final version received August 2007

\begin{abstract}
Summary
The paper develops a two-stage duopoly model to investigate the effects of eliminating subsidies to state trading enterprises (STEs) as discussed in the WTO Doha Development Agenda negotiations on agriculture. Unlike the STE, the private firm may choose to integrate vertically in order to avoid transaction costs arising from dealing with downstream operators. The theoretical model shows that eliminating subsidies to the STE may induce a change in market structure and not necessarily lead to increased competition. In fact, if transaction costs are large enough relative to fixed costs, then the result may be a monopoly by the private firm.
\end{abstract}

Keywords: state trading enterprises, multinational firm, WTO, international market structure

JEL classification: F12, F51, Q17

\section{Introduction}

The July 2004 Framework Agreement and the December 2005 Hong Kong Ministerial Declaration within the WTO Doha Development Agenda (DDA) round make it clear that, if an agreement is reached, it will contain specific disciplines for agricultural exporting state trading enterprises (STEs). According to the Hong Kong Declaration, direct disciplines will be introduced on export subsidies, government financing and the underwriting of losses with the commitment to eliminate these three forms of subsidies to STEs by 2013. In addition, the use of monopoly power will also be disciplined in the future. Since the December 2005 Hong Kong Ministerial, negotiations on this issue have not made appreciable progress.

This tentative agreement is the outcome of the long-standing political debate on the trade-distorting practices of agricultural STEs. Although STE operations are already restricted by the GATT, further regulation has been proposed in the DDA negotiations on agriculture. The most notable proposals regarding exporting STEs are those by the US and the EU (WTO, 2000a, b). The US has demanded the elimination of exclusive rights for STEs and of the 
use of government funds or guarantees to support the STEs. The EU, while asking for the abolition of unfair trade practices in exports, has insisted that the elimination of direct export subsidies is conditional on implicit export subsidies (STEs, certain forms of food aid and export credit) being disciplined in the final agreement. Argentina, Brazil and other Latin American countries in their WTO submissions have also expressed concerns about the potential trade-distorting effects of exporting STEs (WTO, 2001a). ${ }^{1}$

On the other hand, among countries where exporting STEs operate, Australia has stated that '... the extent to which an STE may, or may not, distort trade depends on the particular activities and measures undertaken by the STE concerned' (WTO, 2001b: 4); therefore, any additional disciplines should be introduced on a case-by-case basis.

The basic argument of countries demanding further disciplines is that the agricultural STEs are potentially trade distorting because they benefit from government privileges that are not available to private firms. ${ }^{2}$ The suspicion is that their special status allows STEs to circumvent WTO commitments: their single-desk status (i.e. their exclusive right to buy domestic production and to export) means that they may exert market power, use price discrimination and practice price pooling not 'in accordance with commercial considerations', as stated by GATT Article XVII, but rather with the aim of subsidising domestic agricultural production and exports. Moreover, governments often provide STEs with financial assistance not available to private exporters; if the DDA round ends in success, these forms of support will be eliminated by 2013 .

Various effects of exporting STEs have been examined, such as the tradedistorting effects of single-desk STEs (e.g. Alston and Gray, 2000; Fulton et al., 2001; McCorriston and MacLaren, 2005, 2007), and the trade effects of producer payment schemes used by STEs (e.g. Carter et al., 1998; Hamilton and Stiegert, 2000, 2002; Dong et al., 2006).

The aim of this paper is to analyse the impact of eliminating government subsidies to exporting STEs, as tentatively agreed in the WTO DDA negotiations, and to examine the possible impact of this policy change on market structure. ${ }^{3}$ One of the open issues in the debate over STEs is whether further disciplines for agricultural exporting STEs would improve competition and ensure progress towards free trade in markets dominated by oligopolistic private firms. Although data on market shares of private trading companies and evidence on their market power are rather limited, there is consensus on the significance of their role in a number of international markets where exporting STEs operate. In this respect, the most interesting case is probably

1 The STE issue has also been at the heart of a WTO dispute, with the US complaining about the compliance of the operations by the Canadian Wheat Board with WTO rules.

2 Several contributions have examined the agricultural STE issue within the WTO (e.g. Dixit and Josling, 1997; OECD, 2001; McCorriston and MacLaren, 2002; Abbott and Young, 2004; Young, 2005).

3 Other important issues, like the trade effects of STE monopoly power (and the likely impact of its abolition) and those of the producer payment schemes used by STEs, will not be addressed here. 
the grain trade, where a small number of multinational exporting firms account for a large share of the international market and there are few exits and hardly any new entries (Davies, 1986; Wilson and Dahl, 1999; Hayenga and Wisner, 2000). ${ }^{4}$ The concern is that eliminating STE privileges may reduce their ability to compete in oligopolistic markets and may strengthen the market power of large private trading firms (Fulton et al., 2001; Young, 2005). What the market structure would look like as a result of this, and the impact on trade and welfare, is generally unclear.

A two-stage duopoly model is developed, with market structure being endogenously determined in the first stage of the game. Two key differences between the private firm and the STE are modelled. As is the case in other papers, the distinctive feature of the STE with respect to the private firm is its objective function (e.g. Thursby, 1988; Alston and Gray, 2000; McCorriston and MacLaren, 2005). Although the official objective of exporting STEs is, by and large, the maximisation of the surplus of agricultural producers, what the real objectives pursued by STEs are is quite a controversial issue and some papers have modelled other objective functions (e.g. Carter et al., 1998; Hamilton and Stiegert, 2002; Dong et al., 2006). This paper assumes that the STE, contrary to the private firm which maximises profit, maximises the welfare of agricultural producers. An explanation of how this assumption may influence the results is provided throughout.

Unlike the existing literature, we introduce a second distinction between the two firms, that is, their organisational structure. The private firm may choose between two different exporting modes: either to sell the product to other agents performing downstream functions (indirect exports) or to integrate vertically in the shipping, storage and processing industries in the foreign country (direct exports). The latter, although requiring initial fixed costs generating economies of scale, is chosen by the private firm in order to avoid transaction costs arising from having to negotiate with downstream operators. The motivation for direct exports is, thus, based on the transaction costs approach to vertical integration developed in the literature on multinational firms (Caves, 1996; Markusen, 2002) and, more recently, in international trade theory (Spencer, 2005). Despite the limited literature on multinational trading firms operating in agricultural markets, there is a consensus on the existence of vertical integration and on the significance of scale economies. ${ }^{5}$

In the model developed in this paper, the STE can only operate as a 'pure middleman'; that is, it does not own trading facilities and, therefore, sells the product to other firms that perform most of the international marketing functions. As a result, it does not incur fixed costs generating tangible economies of scale.

4 Hayenga and Wisner (2000) report that in the late 1990s two firms, Cargill and Continental (which was acquired in 1998 by Cargill), accounted for 35 per cent of US grain and oilseed exports and the top four firms accounted for 47 per cent of US wheat exports; Cargill alone accounted for about the 25 per cent of Argentine wheat exports.

5 Case studies have highlighted the extensive upstream and downstream integration processes of multinational trading firms in several agricultural markets (e.g. Chalmin, 1986; Read, 1986; Wilson and Dahl, 1999; Hayenga and Wisner, 2000). 
This means that, if transaction costs in international trade are high, the private firm has a competitive advantage over the STE, since it can decide to skip transaction costs and exploit economies of scale. This assumption is based on the observation that agricultural exporting STEs traditionally do not own trading or processing assets abroad (Carter and Wilson, 1997). ${ }^{6}$ Among the most important agricultural STEs, the Canadian Wheat Board is an example of an STE that makes use of accredited agents to reach final consumers.

The model developed in this paper builds on the game theoretical models of international trade that include multinational firms (e.g. Horstmann and Markusen, 1992; Motta, 1992; Markusen, 2002), even though the setting is substantially different, since it considers specific features of international agricultural trade. In the aforementioned models, private firms invest in the foreign countries to jump the tariffs, whereas in this paper the motive for international integration is the presence of transaction costs. Furthermore, all papers mentioned above assume constant domestic costs and symmetry between firms, whereas this paper introduces increasing marginal costs and asymmetry in firm behaviour and objective functions.

The theoretical model is used to study how the elimination of STE subsidies affects market structure. The trade and welfare effects of possible market structure changes are examined by means of numerical examples. The results show that the elimination of subsidies to the STE may have different impacts on market structure, trade and welfare, depending on the initial values of transaction and fixed costs and of the subsidy.

The paper is organised as follows. Section 2 presents the model. Section 3 determines the feasible equilibria and the impact of the elimination of the subsidies to the STE on market structure. Section 4 discusses the consequence on trade and welfare through a numerical example. Section 5 discusses the implications of the results obtained and offers some concluding remarks.

\section{The model}

The model considers two exporting countries ( $i$ and $j$ ) and one importing country $(z)$ of a homogeneous agricultural product. Exports from country $i$ are managed by a private firm, while an STE has the exclusive right to purchase and export from country $j$. Both firms sell on their own domestic market and export to country $z$. Production in country $z$ is assumed to be zero. This setting is intended to represent competition between two exporting countries on the same export market, with exports carried out by a large private firm in one country and by an STE in the other.

Let $p_{i}, p_{j}$ and $p_{z}$ be the inverse demand curves. Linear functional forms and identical demand in the two exporting countries are assumed: $p_{i}=\alpha-\beta X M_{i}$,

6 Ongoing reforms are in some cases removing this restriction, at least in part. For example, the New Zealand Dairy Board, which accounts for about 30 per cent of world dairy exports, is now a leading multinational dairy company, co-operatively owned by New Zealand dairy farmers. 
$p_{j}=\alpha-\beta X S_{j}$ and $p_{z}=\lambda-\delta\left(X M_{z}+X S_{z}\right)$ with $X M$ and $X S$ being exports / sales of the private firm and of the STE, respectively.

The private firm may export to $z$ either indirectly or directly. In the first case, the firm operates as a 'pure middleman' and sells the product to other agents. With this option, the firm incurs transaction costs, $t_{z}$, per unit exported, which are assumed to be constant. In the second case, the firm integrates downstream to eliminate transaction costs, but this option implies fixed costs, denoted by $G$, including both the cost of acquiring facilities for storage, handling, transportation or processing, and also the information and legal costs necessary to open a subsidiary in a foreign country. The private firm, thus, chooses direct (indirect) exports if transaction costs (fixed costs) are high relative to fixed costs (transaction costs). This hypothesis builds on the literature on the multinational firm, which emphasises that vertical integration is frequently chosen by firms to internalise costly arm's-length transactions (e.g. Caves, 1996; Markusen, 2002). Despite the lack of empirical evidence, there are good arguments to support the hypothesis that transaction costs play a relevant role in the firm's degree of forward integration also in agricultural markets. As for grain, for example, Caves (1977) argues that trading in agricultural products is a time-dependent activity, as the optimal utilisation of trading facilities depends on their available capacity at particular points in time. Opportunism in bargaining processes may lead to high transaction costs and make it advantageous to coordinate such activities within an administrative apparatus rather than at arm's length. For other agricultural commodities, case studies show that one of the reasons for vertical integration by international trading firms is the need to ensure access to supplies without incurring costly transactions with local producers (Chalmin, 1986; Read, 1986).

On the other hand, the STE is assumed to export only indirectly. As its mandate is to operate as a 'pure middleman', it cannot purchase trading or processing assets. As already mentioned, this feature is common to exporting agricultural STEs.

In this model, both firms purchase, sell domestically and export domestic agricultural products only. The inverse supply functions for the agricultural product faced by the STE and the private firm are assumed to be linear and are given, respectively, by $c_{s}=\theta+\rho\left(X S_{j}+X S_{z}\right)$ and $c_{m}=\varphi+\kappa\left(X M_{i}+X M_{z}\right)$.

The firms also bear firm-specific set-up costs $\left(C_{m}\right.$ and $\left.C_{s}\right)$, which include the cost of acquiring intangible assets (e.g. information) that are essential for the trading industry (Caves, 1977). Firm-specific fixed costs are assumed to be high relative to demand, and thus markets can support at most two firms. Furthermore, the said costs are considered to be faced by firms on the domestic market. Markets are assumed to be segmented. ${ }^{7}$

7 Price discrimination by STEs is a much debated issue. Some studies on the international wheat trade conclude that there is a degree of price discrimination by the Canadian Wheat Board (e.g. Brooks and Schmitz, 1999; Lavoie, 2005). 
Two kinds of subsidies to the STEs are considered: a per unit subsidy $s$, which is assumed to be paid on both domestic sales and exports, and a fixed subsidy $U$. The former is aimed at capturing certain government privileges that enable STEs to reduce their variable costs. For example, government guarantees for commercial loans allow STEs to have access to financial resources at a lower interest rate than would otherwise be the case (Carter and Wilson, 1997; Dixit and Josling, 1997). On the other hand, the fixed subsidy $U$ captures other privileges that have the effect of reducing the fixed costs of the STE. For example, the expectation of the government's underwriting of losses may encourage the STE to sustain higher administrative costs (Furtan, 2005); it has also been argued that the government guarantee of STE borrowing and export credit sales creates a 'financial cushion' that the STE may use to recover general expenses (Goodloe, 2004).

The firms play a two-stage game. In the first stage, firms choose the entry strategy; moves in the first stage of the game are assumed to be simultaneous. The possible actions considered in the first stage do not include those where the firm chooses to export to $z$ without selling on the domestic market. Therefore, for the private firm there are four potential strategies, whereas the STE has three. Table 1 shows the payoff matrix of the game. The action set of the firms is given by the combinations of their choices on the domestic and foreign markets. More specifically, the private firm in the domestic market chooses either to enter (in Table 1, this is denoted by $i$ ) or not to enter (denoted by 0 ), whereas in the foreign market it chooses between the noentry option (which is denoted by 0 ), indirect exports (denoted by $z$ ) and direct exports (denoted by $z_{\mathrm{d}}$ ); the action set of the STE is equal to that of the private firm, but does not include the option of direct exports.

In the second stage, the firms play a Cournot game. The game is solved backwards, by first considering the second stage decision. As elsewhere (e.g. Thursby, 1988; Alston and Gray, 2000; McCorriston and MacLaren, 2005), the STE and the private firm are assumed to behave differently. The private firm is assumed to exercise monopsony power with respect to agricultural producers and to maximise its profits. The STE is assumed to maximise the welfare of domestic agricultural producers.

Table 1. The pay-off matrix

\begin{tabular}{|c|c|c|c|c|c|}
\hline & & & \multicolumn{3}{|l|}{ STE } \\
\hline & & & $\begin{array}{l}{[0,0]} \\
0\end{array}$ & $\begin{array}{l}{[j, 0]} \\
1\end{array}$ & $\begin{array}{l}{[j, z]} \\
2\end{array}$ \\
\hline Private firm & $\begin{array}{l}{[0,0]} \\
{[i, 0]} \\
{[i, z]} \\
{\left[i, z_{d}\right]}\end{array}$ & $\begin{array}{l}0 \\
1 \\
2 \\
3\end{array}$ & $\begin{array}{l}0 \\
M^{10}, 0 \\
M^{20}, 0 \\
M^{30}, 0\end{array}$ & $\begin{array}{l}0, S^{01} \\
M^{11}, S^{11} \\
M^{21}, S^{21} \\
M^{31}, S^{31}\end{array}$ & $\begin{array}{l}0, S^{02} \\
M^{12}, S^{12} \\
M^{22}, S^{22} \\
M^{32}, S^{32}\end{array}$ \\
\hline
\end{tabular}


Let $M$ denote the profit of the private firm when it chooses to export indirectly to $z$ :

$$
M=p_{i} X M_{i}+p_{z} X M_{z}-c_{m}\left(X M_{i}+X M_{z}\right)-t_{z} X M_{z}-C_{m}
$$

If the firm maximises its objective function assuming the rival's exports constant (Cournot competition), first-order conditions are given by: ${ }^{8}$

$$
\begin{gathered}
\frac{\mathrm{d} M}{\mathrm{~d} X M_{i}}=-2 \beta X M_{i}+\alpha-\varphi-2 \kappa\left(X M_{i}+X M_{z}\right)=0, \\
\frac{\mathrm{d} M}{\mathrm{~d} X M_{z}}=-2 \delta X M_{z}+\lambda-\delta X S_{z}-\varphi-2 \kappa\left(X M_{i}+X M_{z}\right)-t_{z}=0,
\end{gathered}
$$

from which we obtain

and

$$
X M_{i}=\frac{\alpha-\varphi-2 \kappa X M_{z}}{2(\beta+\kappa)}
$$

$$
X M_{z}=\frac{\lambda-\delta X S_{z}-\varphi-2 \kappa X M_{i}-t_{z}}{2(\delta+\kappa)} .
$$

The STE's objective function is

$$
S=p_{j} X S_{j}+p_{z} X S_{z}+s\left(X S_{j}+X S_{z}\right)+U-\int_{0}^{X S_{j}+X S_{z}} c_{s} \mathrm{~d}\left(X S_{j}+X S_{z}\right)-t_{z} X S_{z}-C_{s} .
$$

First-order conditions are

$$
\begin{gathered}
\frac{\mathrm{d} S}{\mathrm{~d} X S_{j}}=\alpha-2 \beta X S_{j}+s-\theta-\rho X S_{j}-\rho X S_{z}=0 \quad \text { and } \\
\frac{\mathrm{d} S}{\mathrm{~d} X S_{z}}=\lambda-2 \delta X S_{z}-\delta X M_{z}+s-\theta-\rho X S_{j}-\rho X S_{z}-t_{z}=0,
\end{gathered}
$$

which yield

$$
X S_{j}=\frac{\alpha-\theta+s-\rho X S_{z}}{2 \beta+\rho}
$$

8 Scoppola (2007) addresses the issue of how the assumed mode of competition and product homogeneity affect the results in this kind of model, albeit within a rather different setting; unlike this paper, domestic costs are constant, both firms maximise profits and there are two-way trade flows between the exporting countries. 
and

$$
X S_{z}=\frac{\lambda-\delta X M_{z}+s-\theta-\rho X S_{j}-t_{z}}{2 \delta+\rho} .
$$

Using equations (4) and (9), equations (5) and (10) can be solved for $X M_{z}$ and $X S_{z}$ to obtain the duopoly equilibrium exports when the private firm exports indirectly. The quantities exported to $z$ under the outcome $\{2,2\}$ of Table 1 are

$$
X M_{z}^{22}=\frac{A\left[H\left(\lambda-\varphi-t_{z}\right)-E\right]-\delta H\left[D\left(\lambda-\theta-t_{z}+s\right)-F-\rho s\right]}{Q}
$$

and

$$
X S_{z}^{22}=\frac{B\left[D\left(\lambda-\theta-t_{z}+s\right)-F-\rho s\right]-\delta D\left[H\left(\lambda-\varphi-t_{z}\right)-E\right]}{Q},
$$

where $H=\beta+\kappa, \quad D=2 \beta+\rho, \quad E=\kappa(\alpha-\varphi), \quad F=\rho(\alpha-\theta)$, $A=D(2 \delta+\rho)-\rho^{2}, B=2 H(\delta+\kappa)-2 \kappa^{2}$ and $Q=A B-\delta^{2} H D$.

The payoffs to the firms in equilibrium are then derived by substituting the supply and demand functions and the domestic equilibrium quantities into the objective functions (1) and (6), which yields

and

$$
\begin{aligned}
M^{22}= & \frac{(\alpha-\varphi)^{2}}{4 H}+\left(\lambda-\varphi-t_{z}-\frac{E}{H}-\delta X S_{z}^{22}\right) X M_{z}^{22} \\
& -\left(\delta+\kappa-\frac{\kappa^{2}}{H}\right)\left(X M_{z}^{22}\right)^{2}-C_{m}
\end{aligned}
$$

$$
\begin{aligned}
S^{22}= & \frac{(\alpha+s-\theta)^{2}}{2 D}+\left(\lambda+s-\theta-t_{z}-\delta X M_{z}^{22}-\frac{F+\rho s}{D}\right) X S_{z}^{22} \\
& -\frac{1}{2}\left(2 \delta+\rho-\frac{\rho^{2}}{D}\right)\left(X S_{z}^{32}\right)^{2}+U-C_{s} .
\end{aligned}
$$

If the private firm opts for directs exports, then its profits are given by

$$
M=p_{i} X M_{i}+p_{z} X M_{z}-c_{i}\left(X M_{i}+X M_{z}\right)-G-C_{m},
$$

and maximisation leads to the following duopoly equilibrium exports under the outcome $\{3,2\}$ of Table 1 :

$$
X M_{z}^{32}=\frac{A[H(\lambda-\varphi)-E]-\delta H\left[D\left(\lambda-\theta-t_{z}+s\right)-F-\rho s\right]}{Q}
$$


and

$$
X S_{z}^{32}=\frac{B\left[D\left(\lambda-\theta-t_{z}+s\right)-F-\rho s\right]-\delta D[H(\lambda-\varphi)-E]}{Q} .
$$

The payoffs to the firms are then given by

and

$$
\begin{aligned}
M^{32}= & \frac{(\alpha-\varphi)^{2}}{4 H}+\left(\lambda-\varphi-\frac{E}{H}-\delta X S_{z}^{32}\right) X M_{z}^{32} \\
& -\left(\delta+\kappa-\frac{\kappa^{2}}{H}\right)\left(X M_{z}^{32}\right)^{2}-C_{m}-G
\end{aligned}
$$

$$
\begin{aligned}
S^{32}= & \frac{(\alpha+s-\theta)^{2}}{2 D}+\left(\lambda+s-\theta-t_{z}-\delta X M_{z}^{32}-\frac{F+\rho s}{D}\right) X S_{z}^{32} \\
& -\frac{1}{2}\left(2 \delta+\rho-\frac{\rho^{2}}{D}\right)\left(X S_{z}^{32}\right)^{2}+U-C_{s} .
\end{aligned}
$$

The equilibrium exports and the associated payoff in the second stage of the game for all outcomes are reported in Tables A1 and A2 of the Appendix.

As already mentioned, a number of papers have assumed that the STEs do not maximise producer welfare but, rather, that they have other objective functions such as the welfare of the bureaucracy (Carter et al., 1998) or STE profits (Hamilton and Stiegert, 2002; Dong et al., 2006). McCorriston and MacLaren (2007) showed how different objective functions imply different market equilibria. In this model, a different objective function affects not only the equilibrium exports and payoff, but also the market structure, as the payoff to the STE influences its choice in the first stage of the game. A profit-maximising STE always exports less than a welfare-maximising STE: first-order conditions would be similar to those of the private firm exporting indirectly [equations (2) and (3)]. Also the payoff would be similar and, thus, lower than in the case of producer welfare maximisation. The outcomes of the game would differ from those obtained when one assumes an STE maximising producer welfare.

\section{The elimination of STE subsidies: impact on market structure}

Outcomes of this two-stage game may be a Nash equilibrium for certain combinations of the values of parameters. We are primarily interested in analysing how the Nash equilibrium may be affected by a change in the value of government subsidies to the STE, $s$ and $U$, and in the value of $t_{z}$ and $G$, that is, transaction and fixed costs, which in this model crucially determine the action chosen by the private firm. For this purpose, it is first necessary to derive the constraints that must be satisfied for each of these outcomes to be a Nash equilibrium. The analysis is here limited to some of the potential 
solutions of the game, and does not consider market structures in which at least one firm operates domestically only. Although these outcomes are, in theory, the possible solutions of the game, they are in fact less relevant in the context of the debate on the trade-distorting effects of subsidies to STEs, and hence, for the specific purpose of this paper.

Consider outcome $\{2,2\}$ of the game (Table 1). This is a Nash equilibrium if each firm chooses the best response to the action chosen by the rival, that is, the action that maximises its payoff given the action of the rival. This requires (i) $M^{22}>0$, (ii) $M^{22}>M^{32}$ and (iii) $S^{22}>0$ with $X M_{z}^{22}, X M_{i}^{22}, X S_{z}^{22}, X S_{j}^{22}>0$.

By substituting the equilibrium quantities into equation (13) with equations (11) and (12), constraint (i) may be written as

$$
M^{22}=\Omega+\Psi t_{z}^{2}+\Delta t_{z}+\Pi s+\Phi s^{2}+\Gamma s t_{z}-C_{m}>0,
$$

where $\Omega, \Psi, \Delta, \Pi, \Phi$ and $\Gamma$ depend upon demand and supply function parameters. Using equations (13) and (18), constraint (ii) may be written as

$$
\Psi^{\prime} t_{z}^{2}+\Delta^{\prime} t_{z}+\Gamma^{\prime} s t_{z}>-G
$$

while using equation (14), constraint (iii) may be written as

$$
S^{22}=\zeta+\varepsilon t_{z}^{2}+\varpi t_{z}+v s+\tau s^{2}+\mu s t_{z}+U-C_{s}>0,
$$

where again $\zeta, \varepsilon, \varpi, v, \tau$ and $\mu$ are functions of demand and supply function parameters only.

The same procedure has been used to derive a complete set of constraints for all other outcomes. ${ }^{9}$

Each set of constraints defines a region in the parameter space where the corresponding market structure is a Nash equilibrium. Before analysing how the subsidies to the STE influence the outcome of the game, consider first how the Nash equilibrium is affected by different values of costs to export to market $z$. If $t_{z}$ is large relative to $G$, then the optimal choice of the private firm, whatever the choice of the STE, is to export directly to market $z$. The greater $t_{z}$, the more the STE is at a disadvantage. If transaction costs become very high, payoff to the STE becomes negative and its optimal choice is the no-entry option. On the other hand, if $G$ is high enough, the private firm opts for indirect exports and the STE enters because its payoff becomes positive. If both $t_{z}$ and $G$ are very high, then duopoly profits may become negative.

Figure 1 illustrates the possible outcomes of the game in $\left\{t_{z}, G\right\}$ space, when the STE does not receive any subsidy from its government and under the

9 The complete set of constraints to be satisfied for each outcome of the game to be a Nash equilibrium is not reported due to the space constraint. However, they are available from the author upon request. 


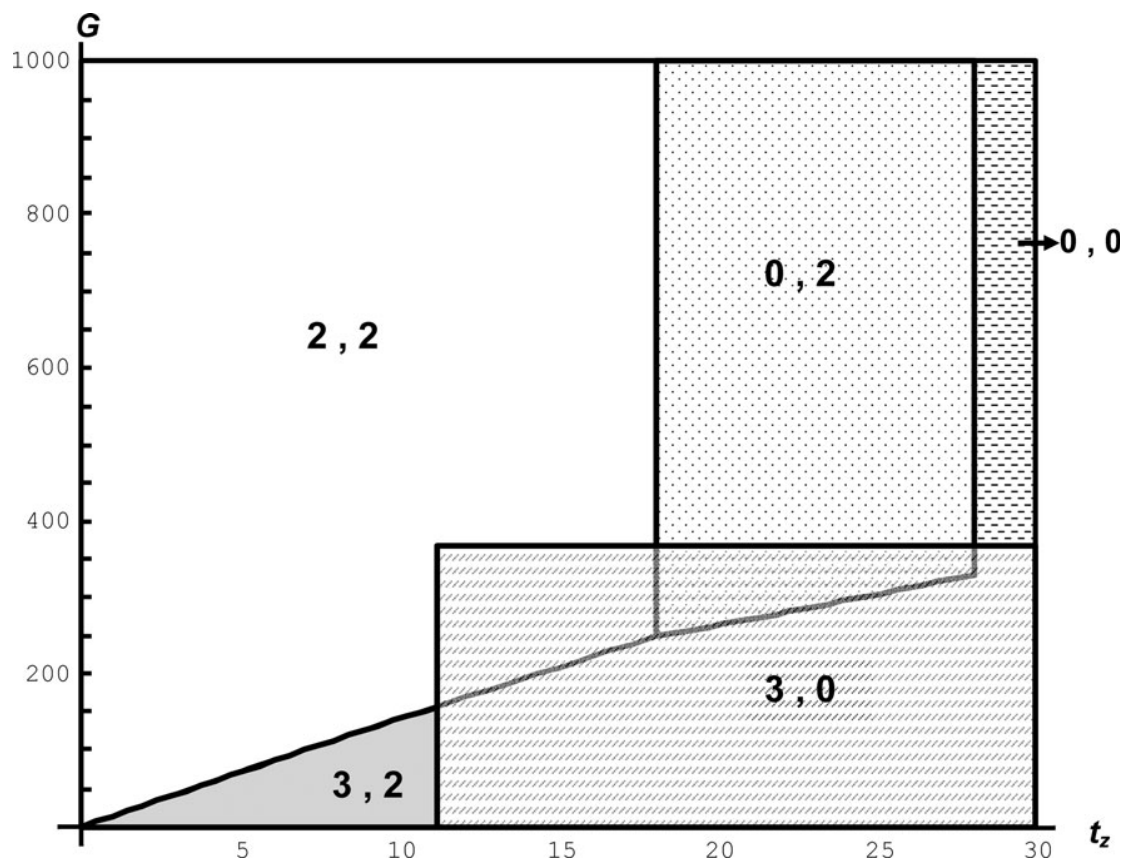

Figure 1. Market regimes as a function of transaction and fixed costs $(s=U=0)$. Market structures are denoted by the corresponding payoff matrix outcome. More specifically, $\{2,2\}$ denotes a duopoly, with the private firm exporting indirectly; $\{3,2\}$ a duopoly with the private firm exporting directly; $\{0,2\}$ a monopoly of the STE and $\{3,0\}$ a monopoly of the private firm when it exports directly; in $\{0,0\}$ both firms do not enter.

assumption of cost symmetry between firms. ${ }^{10}$ If the firms face the same costs and do not receive any subsidy, then differences between them depend upon two factors: differences in their organisational structure and/or their different pricing behaviour as a result of the differences in their objective functions.

When both $G$ and $t_{z}$ are zero, regimes $\{2,2\}$ and $\{3,2\}$ are equivalent. In this case, the key difference between the two firms is the one in their objective function: the private firm exercises monopsony power with respect to domestic producers and its marginal cost is lower than the competitive price, whereas the STE marginal cost is the competitive supply price. This equilibrium corresponds to that obtained in contributions assuming exogenous market structure and zero fixed costs (e.g. Thursby, 1988; McCorriston and MacLaren, 2005).

If transaction costs are positive, however, market structure may change. Figure 1 shows that there are three critical values of $t_{z}$ above which a

10 Firms' costs symmetry is here ensured by assuming identical supply function parameters and equal domestic fixed costs. 
regime shift occurs. ${ }^{11}$ The lower critical value of $t_{z}$ (in Figure $1, t_{z}=11$ ) is defined by the constraints of regimes $\{3,2\}$ and $\{3,0\}$. Assume first that the fixed costs are zero. When transaction costs are below that lower critical value, regime $\{3,2\}$ prevails; in this regime, firms also differ because of their degree of integration and this implies that, with respect to the market structure $\{2,2\}$, the private firm's exports and payoff are higher $\left(X M_{z}^{32}>X M_{z}^{22}\right.$ and $\left.M^{32}>M^{22}\right)$, whereas those of the STE are lower $\left(X S_{z}^{32}<X S_{z}^{22}\right.$ and $S^{32}<S^{22}$ ). This is because the former skips transaction costs and increases its exports at the expense of the latter. When transaction costs are above the lower critical value, the STE chooses the no-entry option and a monopoly of the private firm, i.e. regime $\{3,0\}$, is the outcome of the game.

Consider now the effect of an increase in fixed costs. If transaction costs are below the lower critical value, an increase in fixed costs results in a change in the private firm's export strategy from direct exports (region $\{3,2\}$ ) to indirect exports (region $\{2,2\}$ ). This regime shift implies an increase in the STE's market share at the expense of the private firm. But when transaction costs are between the lower and the higher critical value, then the initial regime is $\{3,0\}$. An increase in fixed costs, and the resulting change in the entry strategy of the private firm, makes the STE payoff positive. As a result, when transaction costs are smaller than the intermediate critical value, the regime shifts from a monopoly, i.e. $\{3,0\}$, towards a duopoly, that is, $\{2,2\}$ (in Figure 1, this occurs for $11<t_{z}<17$ ). However, if transaction costs are higher than the intermediate critical level, then an increase in $G$ makes direct exports infeasible, while duopoly profits become negative because of the high transaction costs. In this case, the feasible equilibrium is a monopoly of the STE $\{0,2\}$ (in Figure 1, this occurs for $17<t_{z}<28$ ). The intuition behind this result is that when fixed costs are high, the private firm cannot exploit its structural advantage; if transaction costs are also high and duopoly profits are negative, the payoff to the private firm becomes negative, while that of the STE can still be positive. This is due to the different behaviour of the two firms. Although the payoff to the private firm is the result of monopoly and monopsony profits, the STE payoff includes monopoly profits. It is possible that the STE payoff is positive, whereas it is negative for the private firm. Thus, when both transaction and fixed costs are high, the particular objective function of the STE may provide it with a strategic advantage with respect to the private firm.

When transaction costs become greater than the higher critical value (in Figure $1, t_{z}>28$ ), and fixed costs are high enough, then both firms face negative payoffs and opt for the no-entry option.

The feasible equilibria illustrated in Figure 1 would be somewhat different if the STE were assumed to maximise the profit instead of its producers' welfare. First, assuming cost symmetry between firms and a profit-maximising STE, market regime $\{0,2\}$ would never be a feasible equilibrium, as in this

11 The critical values of $t_{z}$ illustrated in Figure 1 are driven by the binding constraints to be satisfied for each outcome to be a Nash equilibrium. The overlapping of regime $\{3,0\}$ with regimes $\{2,2\}$ and $\{0,2\}$ denotes a multiple Nash equilibria area. 
case the payoff to the STE would never be greater than that to the private firm. The second difference is in the critical values of transaction costs above which the market regime of the private firm shifts to a monopoly; this would be lower than in Figure 1, because with the profit maximising STE the payoff becomes negative for lower values of transaction costs.

Figure 2 illustrates the Nash equilibrium as a function of $t_{z}$ and the subsidy $s$, assuming again that $U=0 .{ }^{12}$ As already illustrated in Figure 1, when the subsidy is zero, and transaction costs are smaller than the lower critical level $\left(t_{z}<11\right)$, there is a duopoly (regime $\{2,2\}$ ). A relatively small subsidy does not change market structure, even though it changes market shares to the advantage of the STE. If $t_{z}>11$, then the private firm opts for direct exports and this implies a monopoly of the multinational firm (regime $\{3,0\})$. In this case, an increase in subsidy $s$ allows the STE to enter the market despite its structural disadvantage. In Figure 2, even with high transaction costs, a per unit subsidy equal to 5 is high enough to make the STE payoff positive. Clearly, the higher the transaction costs, and thus the

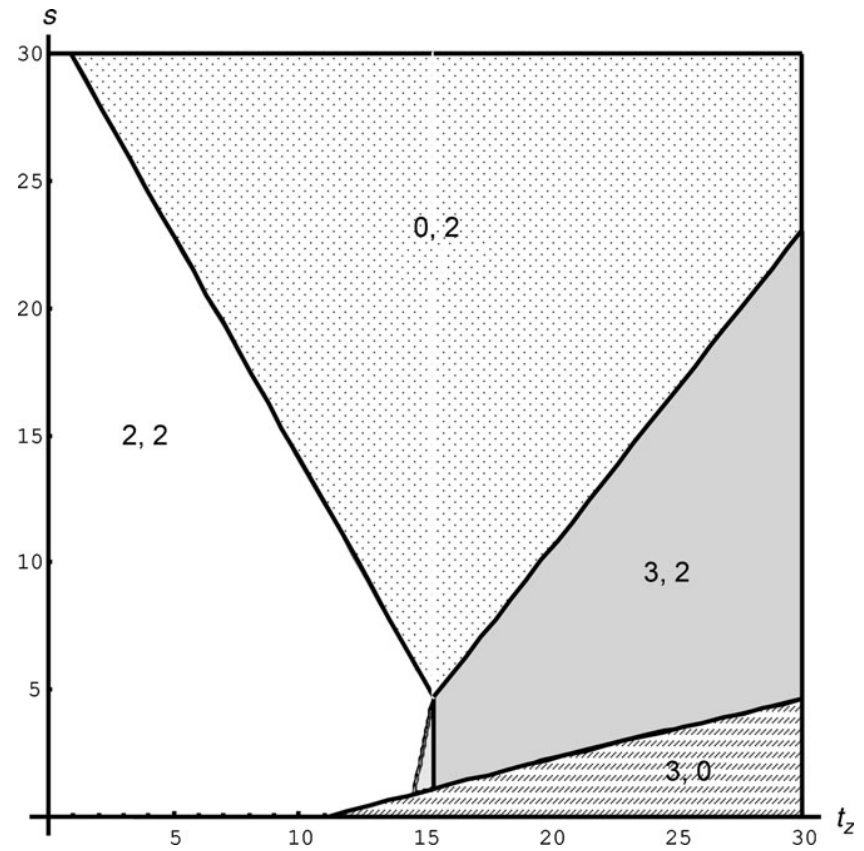

Figure 2. Market regimes as a function of transaction costs and the subsidy $s(U=0)$. Market structures are denoted by the corresponding payoff matrix outcome. More specifically, $\{2,2\}$ denotes a duopoly, with the private firm exporting indirectly; $\{3,2\}$ a duopoly with the private firm exporting directly; $\{0,2\}$ a monopoly of the STE and $\{3,0\}$ a monopoly of the private firm when it exports directly. 
disadvantage of the STE, the greater the subsidy needed to make the STE payoff positive. Figure 2, therefore, shows that a subsidy to the STE may re-establish a duopoly and 'compensate' the STE for the high transaction costs it faces with respect to its rival.

If subsidy $s$ is high, an STE monopoly may be the outcome (regime $\{0,2\}$ ). The critical value of $s$ above which regime $\{0,2\}$ prevails depends on transaction costs. More specifically, if $t_{z}$ is low enough $\left(t_{z}<15\right)$, then the higher the transaction costs, the lower the critical value of the subsidy.

Conversely, if $t_{z}>15$, the higher the transaction costs, the higher the subsidy needed to shift the regime to a monopoly of the STE. This is because when transaction costs are high and the private firm enters through direct exports, an increase in transaction costs reduces the payoff only to the STE. Consequently, the level of subsidy necessary to shift to an STE monopoly increases with transaction costs. On the contrary, when the private firm also faces transaction costs, then the critical value of the subsidy decreases with transaction costs.

What is the impact, then, of eliminating the subsidy to the STE? Clearly, it depends on the initial level of the subsidy and on the value of transaction costs.

If transaction costs are below the lower critical value (in Figure $2, t_{z}<11$ ) and the subsidy is such that the initial regime falls in region $\{2,2\}$, then market structure does not change. Even after the elimination of the subsidy, both firms continue to export to the third market, even though the private firm's market share increases at the expense of that of the STE. Conversely, if the value of $s$ is such that the initial regime is $\{0,2\}$, then eliminating the subsidy may allow the private firm to enter the market and, thus, a duopoly prevails. Finally, if transaction costs are larger than the lower critical value $\left(t_{z}>11\right)$, then the elimination of the subsidy, whatever the initial regime and the value of the subsidy, will result in the exit of the STE $(\{3,0\})$.

These findings differ only slightly if one assumes the STE maximises profits. The feasible equilibria would be the same, even though the critical values of subsidies above which market structure changes would be different. More specifically, with a profit-maximising STE, a monopoly of the private firm exporting directly would prevail even with relatively high values of the subsidy to the STE. Regimes $\{0,2\}$ and $\{3,2\}$ would be feasible equilibria only for higher values of $s$ to the STE. Therefore, the direction of the impact of eliminating the STE subsidy would be the same as that depicted above, even though the 'point' at which market structure changes would be different.

The impact on market structure of subsidies that enable the STE to reduce fixed costs is rather different. Figure 3 shows the Nash equilibrium regimes in the $\left\{t_{z}, U\right\}$ space, under the assumption that $s=0$.

It is worth noting that, if transaction costs are not too high (in Figure 3, $t_{z}<11$ ), unlike $s$, a fixed subsidy does not affect market structure: even high values of $U$ do not shift market structure away from regime $\{2,2\}$. This is because the entry decision of the private firm is affected by the STE's variable costs, but not by its fixed costs. Therefore, for low values of 


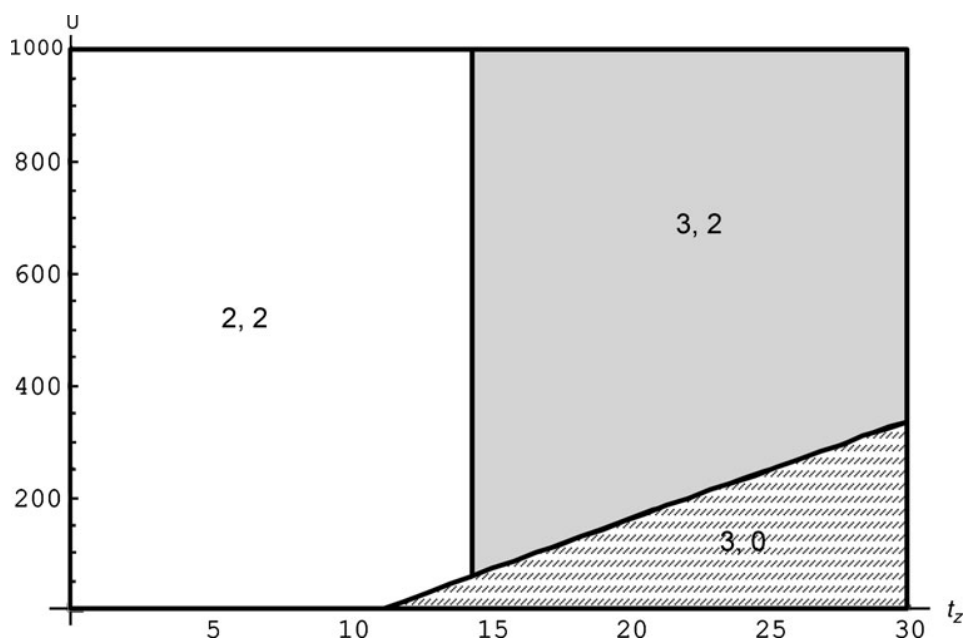

Figure 3. Market regimes as a function of transaction costs and the subsidy $U(s=0)$. Market structures are denoted by the corresponding payoff matrix outcome. More specifically, $\{2,2\}$ denotes a duopoly, with the private firm exporting indirectly; $\{3,2\}$ a duopoly with the private firm exporting directly and $\{3,0\}$ a monopoly of the private firm when it exports directly.

$t_{z}$, the private firm opts for indirect exports in any case, and $U$, although increasing the STE's payoff, does not have any effect: market structure, exports and market shares do not change. ${ }^{13}$

However, if transaction costs are high and the private firm opts for direct exports, then the level of $U$ may affect the STE's decision regarding entry: high values of $U$ allow the STE to enter the market and to compete with the private firm, while with low values of $U$ a multinational monopoly prevails.

Therefore, the impact of eliminating the subsidy that reduces the STE's fixed costs may be negligible if transaction costs are low and the private firm exports indirectly. However, if transaction costs are high relative to fixed costs and the multinational already exports directly, then eliminating the subsidy may shift the regime from a duopoly to a monopoly. ${ }^{14}$

Overall, the findings of the model suggest that the effects of eliminating STE subsidies may or may not change the market structure depending on the initial regime, which is a function of the values of $t_{z}, G, s$ and $U$. If before the policy change there is a duopoly, but the private firm has a

13 In this model, it is assumed that the agricultural producers of country $j$ produce the equilibrium quantities, and that the redistribution of possible STE profits to them does not affect their production decision.

14 It is worth noting that, also in this case, the feasible equilibria would not change under the assumption that the STE maximises profit, even though the critical values of the fixed subsidy above which regime $\{3,2\}$ is a feasible equilibrium would be much higher than in Figure 3. 
strong competitive advantage because of high transaction costs relative to fixed costs, then eliminating subsidy $s$ may cause a change in market structure, with a shift to a monopoly of the private firm. Conversely, if transaction costs are low enough, eliminating $s$ may or may not induce a change in market structure, depending on the initial value of $s$ in relation to $t_{z}$ : the higher $s$ with respect to $t_{z}$, the lower the possibility of a regime shift.

One implication of these findings is that, when assessing the impact of eliminating STE subsidies, one should first consider the key features characterising each export market-in particular, whether or not the private traders are vertically integrated in that specific export market, and whether or not the subsidy granted to the STE is high enough to give the STE a substantial strategic advantage. When looking at the competition between private traders and STEs in a variety of markets, several situations may arise. For example, one key difference is between export markets where an importing STE operates and countries where imports are managed by private traders. In the former countries, as importing STEs have often the exclusive right to import, private exporters cannot be vertically integrated and, therefore, do not exploit economies of scale and their potential for a more efficient marketing structure, whereas the exporting STE exploits the advantages of its peculiar mandate and nature, even strengthened by the fact that importing STEs prefer to deal with exporting STEs, rather than with private traders. ${ }^{15}$ In this case, subsidy elimination may keep the STE's payoff positive. The impact would be very different in countries where private exporters are able to integrate vertically. In that case, subsidy elimination could threaten the STE's ability to compete with the private firm, as is the case when the subsidies counterbalance the STE's structural disadvantage. ${ }^{16}$

The results obtained also show that eliminating a per unit subsidy $(s)$ may have quite a different impact from the removal of a fixed subsidy $(U)$. The main difference is that, while the value of $s$ influences the decisions of both firms, subsidies affecting the fixed costs of the STE determine the entry choice of the STE only. This means that removing these subsidies may affect market structure as long as it causes the STE payoff to become negative; that is, only if before the policy change the STE's disadvantage with respect to the private firm is so large that without subsidies the STE cannot enter the market. In this model, this is likely to happen when transaction costs are high with respect to fixed costs.

A further implication is that the trade and welfare effects of a policy shock are different from those predicted by models that consider market structure as

15 This evidence has been brought to my attention by one of the referees.

16 As for US-Canada competition in the grain trade, there are importing countries (like Algeria and Morocco) where Canada accounts for a relevant share of the market, while US exports are negligible. In markets, where the USA and Canada compete for market share, private firms are sometimes vertically integrated (like Cargill in the EU and in Indonesia), while in other cases they sell to an importing STE (e.g. Cargill in Japan) (Kneen, 2002). Finally, in a number of importing countries, the US multinational firms account for a major share of the market and do not compete with the Canadian Wheat Board (e.g. Egypt and the Republic of Korea). 
exogenous and ignore economies of scale. These models, in fact, assume that market structure cannot change and that firms are identical with respect to their degree of forward integration and that the market structure is always the duopoly regime $\{2,2\}$. If in Figure 2 one assumes exogenously regime $\{2,2\}$ as market structure, then eliminating subsidy $s$ would not make the STE payoff negative; on the contrary, when transaction costs are high, the private firm is vertically integrated and eliminating $s$ makes market structure shift to a monopoly of the multinational firm. Likewise, eliminating $U$ may have no trade effect if the private firm is assumed to export only indirectly, whereas in our model it may induce a shift to a monopoly of the multinational firm if the latter is vertically integrated. As shown in the following section, the trade and welfare effects of STE subsidy elimination may be very different when market structure changes.

\section{Trade and welfare effects of eliminating STE subsidies: numerical examples}

The trade and welfare effects of the changes in market structure discussed in the previous section are illustrated here by means of numerical examples. ${ }^{17}$ Table 2 presents the changes in total exports, prices and market shares in country $z$ when transaction and fixed costs change and the STE subsidies are zero, under the various possible market structures illustrated in Figure 1. Table 3 provides the corresponding changes in welfare. For country $i$, welfare is obtained by aggregating the profits of the firm and domestic producer and consumer surpluses, while for country $j$, welfare is the sum of the payoff to the STE and consumer surplus, minus government expenditure. In country $z$, welfare is given by consumer surplus only. The percentage changes in the tables are calculated with respect to the benchmark $t_{z}=G=U=s=0$.

Table 2 shows that in regime $\{2,2\}$ the STE's market share is always higher than that of the private firm. In this regime, STE exports are well above the level of a profit-maximising firm exerting monopsony power with respect to domestic producers. In addition, within area $\{2,2\}$, an increase in transaction costs further increases the STE's share at the expense of the private firm; welfare in country $i$ diminishes more than in country $j$, essentially because of the steep decline in the private firm's profits. Overall welfare declines.

Things change if market structure changes. The trade effects when a shift towards regime $\{3,2\}$ occurs are rather different: the private firm gains substantial market share, as it skips transaction costs and increases exports at the expense of the STE; the increase in the private firm's exports may be

17 In the numerical examples, the values of demand and supply parameters are the following: $\alpha=30, \beta=1, \lambda=60, \delta=1, \varphi=5, \rho=0.5, \theta=5, \kappa=0.5$. As for the other variables, we set $C_{m}=C_{s}=180$. Parameters have been chosen to ensure that equilibrium quantities and prices are positive. Quantities and prices in countries $i$ and $j$ are not reported due to space limitations. For the same reason, the various welfare components are not reported in the tables. All this information is available from the author. 
Table 2. Exports, prices and market shares as a function of transaction and fixed costs $(s=U=0)$

\begin{tabular}{|c|c|c|c|c|c|c|c|}
\hline \multirow[t]{2}{*}{$G$} & & \multicolumn{6}{|l|}{$t_{z}$} \\
\hline & & 0 & 3 & 5 & 10 & 15 & 20 \\
\hline \multirow[t]{6}{*}{500} & $X M_{\mathrm{z}}$ & 100 & 89 & 77 & 66 & 55 & 0 \\
\hline & $X S_{z}$ & 100 & 90 & 81 & 71 & 62 & 65 \\
\hline & $X_{z}$ & 100 & 90 & 79 & 69 & 59 & 38 \\
\hline & $P_{z}$ & 100 & 108 & 117 & 126 & 134 & 152 \\
\hline & STE market share & 58.3 & 58.8 & 59.3 & 60.1 & 61.1 & 100 \\
\hline & $M$ market share & 41.7 & 41.2 & 40.7 & 39.9 & 38.9 & 0 \\
\hline \multirow[t]{6}{*}{400} & $\mathrm{XM}_{\mathrm{z}}$ & 100 & 89 & 77 & 66 & 55 & 0 \\
\hline & $X S_{z}$ & 100 & 90 & 81 & 71 & 62 & 65 \\
\hline & $X_{z}$ & 100 & 90 & 79 & 69 & 59 & 38 \\
\hline & $P_{z}$ & 100 & 108 & 117 & 126 & 134 & 152 \\
\hline & STE market share & 58.3 & 58.8 & 59.3 & 60.1 & 61.1 & 100 \\
\hline & $M$ market share & 41.7 & 41.2 & 40.7 & 39.9 & 38.9 & 0 \\
\hline \multirow[t]{6}{*}{300} & $X M_{z}$ & 100 & 89 & 77 & 66 & 55 & 0 \\
\hline & $X S_{z}$ & 100 & 90 & 81 & 71 & 62 & 65 \\
\hline & $X_{z}$ & 100 & 90 & 79 & 69 & 59 & 38 \\
\hline & $P_{z}$ & 100 & 108 & 117 & 126 & 134 & 152 \\
\hline & STE market share & 58.3 & 58.8 & 59.3 & 60.1 & 61.1 & 100 \\
\hline & $M$ market share & 41.7 & 41.2 & 40.7 & 39.9 & 38.9 & \\
\hline \multirow[t]{6}{*}{200} & $X M_{z}$ & 100 & 89 & 77 & 66 & 152 & 152 \\
\hline & $X S_{z}$ & 100 & 90 & 81 & 71 & 0 & 0 \\
\hline & $X_{z}$ & 100 & 90 & 79 & 69 & 64 & 64 \\
\hline & $P_{z}$ & 100 & 108 & 117 & 126 & 130 & 130 \\
\hline & STE market share & 58.3 & 58.8 & 59.3 & 60.1 & 0 & 0 \\
\hline & $M$ market share & 41.7 & 41.2 & 40.7 & 39.9 & 100 & 100 \\
\hline \multirow[t]{6}{*}{100} & $X M_{z}$ & 100 & 89 & 77 & 124 & 152 & 152 \\
\hline & $X S_{z}$ & 100 & 90 & 81 & 54 & 0 & 0 \\
\hline & $X_{z}$ & 100 & 90 & 79 & 83 & 64 & 64 \\
\hline & $P_{z}$ & 100 & 108 & 117 & 114 & 130 & 130 \\
\hline & STE market share & 58.3 & 58.8 & 59.3 & 37.7 & 0 & 0 \\
\hline & $M$ market share & 41.7 & 41.2 & 40.7 & 62.3 & 100 & 100 \\
\hline \multirow[t]{6}{*}{0} & $X M_{z}$ & 100 & 108 & 116 & 124 & 152 & 152 \\
\hline & $X S_{z}$ & 100 & 85 & 69 & 54 & 0 & 0 \\
\hline & $X_{z}$ & 100 & 94 & 89 & 83 & 64 & 64 \\
\hline & $P_{z}$ & 100 & 104 & 109 & 114 & 130 & 130 \\
\hline & STE market share & 58.3 & 52.3 & 45.5 & 37.7 & 0 & 0 \\
\hline & $M$ market share & 41.7 & 47.7 & 54.5 & 62.3 & 100 & 100 \\
\hline
\end{tabular}

Note: Typeface: regular, regime $\{2,2\}$; bold, regime $\{3,2\}$; italic, regime $\{0,2\}$; bold italic, regime $\{3,0\}$. 
Table 3. Welfare as a function of transaction and fixed costs $(s=U=0)$

\begin{tabular}{|c|c|c|c|c|c|c|c|}
\hline \multirow[t]{2}{*}{$G$} & & \multicolumn{6}{|l|}{$t_{z}$} \\
\hline & & 0 & 3 & 5 & 10 & 15 & 20 \\
\hline \multirow[t]{4}{*}{500} & $W_{i}$ & 100 & 76 & 54 & 36 & 21 & 0 \\
\hline & $W_{j}$ & 100 & 80 & 63 & 47 & 34 & 38 \\
\hline & $W_{z}$ & 100 & 80 & 63 & 48 & 35 & 14 \\
\hline & Total welfare & 100 & 79 & 61 & 45 & 31 & 19 \\
\hline \multirow[t]{4}{*}{400} & $W_{i}$ & 100 & 76 & 54 & 36 & 21 & 0 \\
\hline & $W_{j}$ & 100 & 80 & 63 & 47 & 34 & 38 \\
\hline & $W_{z}$ & 100 & 80 & 63 & 48 & 35 & 14 \\
\hline & Total welfare & 100 & 79 & 61 & 45 & 31 & 19 \\
\hline \multirow[t]{4}{*}{300} & $W_{i}$ & 100 & 76 & 54 & 36 & 21 & 0 \\
\hline & $W_{j}$ & 100 & 80 & 63 & 47 & 34 & 38 \\
\hline & $W_{z}$ & 100 & 80 & 63 & 48 & 35 & 14 \\
\hline & Total welfare & 100 & 79 & 61 & 45 & 31 & 19 \\
\hline \multirow[t]{4}{*}{200} & $W_{i}$ & 100 & 76 & 54 & 36 & 135 & 135 \\
\hline & $W_{j}$ & 100 & 80 & 63 & 47 & 0 & 0 \\
\hline & $W_{z}$ & 100 & 80 & 63 & 48 & 40 & 40 \\
\hline & Total welfare & 100 & 79 & 61 & 45 & 47 & 47 \\
\hline \multirow[t]{4}{*}{100} & $W_{i}$ & 100 & 76 & 54 & 104 & 193 & 193 \\
\hline & $W_{j}$ & 100 & 80 & 63 & 25 & 0 & 0 \\
\hline & $W_{z}$ & 100 & 80 & 63 & 69 & 40 & 40 \\
\hline & Total welfare & 100 & 79 & 61 & 62 & 59 & 59 \\
\hline \multirow[t]{4}{*}{0} & $W_{i}$ & 100 & 119 & 140 & 162 & 250 & 250 \\
\hline & $W_{j}$ & 100 & 70 & 45 & 25 & 0 & 0 \\
\hline & $W_{z}$ & 100 & 89 & 79 & 69 & 40 & 40 \\
\hline & Total welfare & 100 & 89 & 80 & 74 & 71 & 71 \\
\hline
\end{tabular}

Note: Typeface: regular, regime $\{2,2\}$; bold, regime $\{3,2\}$; italic, regime $\{0,2\}$; bold italic, regime $\{3,0\}$.

sufficiently high to ensure an increase in total exports. This happens in the example when $G=100$ and $t_{z}$ increases from 5 to 10 . Price in market $z$ falls and welfare of countries $i$ and $z$ improves, while that of country $j$ drastically worsens. Producer welfare increases in country $i$ and declines in the STE's home country. Overall welfare may improve; this means that an increase in transaction costs inducing the private firm to change its export strategy may be less harmful for world welfare than one that does not change market structure. The costs of this change in market structure are borne by producers in country $j$, whose welfare declines significantly.

A sharper increase in transaction costs implies a shift from a duopoly to a monopoly of the private firm, i.e. regime $\{3,0\}$. The numerical example confirms expectations: as a consequence of this shift in regime, a sharp decrease in overall exports to $z$ and a price rise imply a worsening of total welfare. Only 
the private firm and producers in country $i$ benefit from this change in market structure.

When transaction and fixed costs are high enough for regime $\{0,2\}$ to be a Nash equilibrium, the trade and welfare effects are also straightforward. With an STE monopoly, exports are lower and price in market $z$ higher than under the duopoly $\{2,2\}$; the winners are producers in country $j$ whereas the other two countries are worse off. An interesting insight from Table 3 is that the overall welfare in regime $\{0,2\}$, everything else being equal, is lower than in the case of a monopoly of a vertically integrated firm, regime $\{3,0\}$. This is because exports are higher ${ }^{18}$ and, thus, country $z$, is better off. The gains for producers in country $i$, for the private firm and for consumers in country $z$, are thus larger than the losses of producers in country $j$.

The trade and welfare effects of the regime shifts due to a change in subsidy $s$, illustrated in Figure 2, are reported in Tables 4 and 5. Figure 2 shows that eliminating $s$ does not change the market structure when initially regime $\{2,2\}$ is a Nash equilibrium, and when $t_{z}$ is below the critical value. As expected, eliminating $s$ implies an increase in the private firm's market share at the expenses of the STE. As a consequence, however, total exports decline and price in market $z$ increases because, under regime $\{2,2\}$, exports by the profit-maximising firm exerting monopsony power are lower than those of the STE maximising producers' welfare. ${ }^{19}$ In this case, the only winner is country $i$, which benefits from the higher profits of the private firm and higher producer surplus, whereas both countries $j$ and $z$ are worse off. In country $j$, the sharp decline in producer surplus is not compensated for by the decrease in government expenditure, if $s$ is initially low enough (in our example, $s \leq 8$ ). The elimination of subsidies to the STE without any change in market structure makes overall welfare decline.

When the initial values of $s$ and $t_{z}$ are such that the private firm's profits are negative and regime $\{0,2\}$ is a Nash equilibrium, the effects of subsidy elimination depend on the initial value of $t_{z}$. As already mentioned, when $t_{z}$ is below the critical value $\left(t_{z}<11\right)$, then the regime shifts to a duopoly, but this may or may not imply an increase in trade. In our example, if the initial subsidy is high enough $(s=25)$, then the shift towards duopoly $\{2,2\}$ does not increase overall exports. This is because the decline in STE exports is not compensated for by the entry of the private firm. As a consequence, country $z$ does not benefit from the duopoly and is made worse off. Country $j$, although reducing its exports, is better off, as the losses in the producers' and consumers' surplus are smaller than the reduction in public expenditure. Clearly, country $i$ improves its welfare. The shift from an STE monopoly to a duopoly implies, as expected, an increase in overall welfare.

18 From Table A1 of the Appendix, it is easy to show that under cost symmetry and when $s=0$, $X S_{z}^{02}<X M_{z}^{30}$.

19 If the STE maximises profit, an increase in the private firm's market share at the expense of the STE, due to a reduction of $s$, would reduce total exports and increase the price in market $z$ less. 
Table 4. Exports, prices and market shares as a function of transaction costs and the subsidy $s(U=0 ; G=200)$

\begin{tabular}{|c|c|c|c|c|c|c|c|}
\hline \multirow[t]{2}{*}{$s$} & & \multicolumn{6}{|l|}{$t_{\mathrm{z}}$} \\
\hline & & 0 & 3 & 5 & 10 & 15 & 20 \\
\hline \multirow[t]{6}{*}{0} & $X M_{z}$ & 100 & 89 & 77 & 66 & 152 & 152 \\
\hline & $X S_{z}$ & 100 & 90 & 81 & 71 & 0 & 0 \\
\hline & $X_{z}$ & 100 & 90 & 79 & 69 & 64 & 64 \\
\hline & $P_{z}$ & 100 & 108 & 117 & 126 & 130 & 130 \\
\hline & STE market share & 58.3 & 58.8 & 59.3 & 60.1 & 0 & 0 \\
\hline & $M$ market share & 41.7 & 41.2 & 40.7 & 39.9 & 100 & 100 \\
\hline \multirow[t]{6}{*}{2} & $X M_{z}$ & 97 & 86 & 75 & 64 & 130 & 152 \\
\hline & $X S_{z}$ & 105 & 95 & 86 & 76 & 43 & 0 \\
\hline & $X_{z}$ & 102 & 91 & 81 & 71 & 79 & 64 \\
\hline & $P_{z}$ & 98 & 107 & 115 & 124 & 117 & 130 \\
\hline & STE market share & 60.1 & 60.7 & 61.5 & 62.6 & 31.9 & 0 \\
\hline & $M$ market share & 39.9 & 39.3 & 38.5 & 37.4 & 68.1 & 100 \\
\hline \multirow[t]{6}{*}{4} & $X M_{z}$ & 95 & 84 & 72 & 61 & 127 & 135 \\
\hline & $X S_{z}$ & 110 & 100 & 91 & 81 & 48 & 33 \\
\hline & $X_{z}$ & 104 & 93 & 83 & 73 & 81 & 76 \\
\hline & $P_{z}$ & 96 & 105 & 114 & 123 & 115 & 120 \\
\hline & STE market share & 61.8 & 62.6 & 63.7 & 65.0 & 34.7 & 25.4 \\
\hline & $M$ market share & 38.2 & 37.4 & 36.3 & 35.0 & 65.3 & 74.6 \\
\hline \multirow[t]{6}{*}{6} & $X M_{z}$ & 92 & 81 & 70 & 58 & 0 & 133 \\
\hline & $X S_{z}$ & 115 & 105 & 96 & 86 & 90 & 38 \\
\hline & $X_{z}$ & 105 & 95 & 85 & 74 & 53 & 77 \\
\hline & $P_{z}$ & 95 & 104 & 112 & 121 & 139 & 119 \\
\hline & STE market share & 63.5 & 64.5 & 65.7 & 67.3 & 100 & 28.5 \\
\hline & $M$ market share & 36.5 & 35.5 & 34.3 & 32.7 & 0 & 71.5 \\
\hline \multirow[t]{6}{*}{8} & $X M_{z}$ & 90 & 78 & 67 & 56 & 0 & 130 \\
\hline & $X S_{z}$ & 120 & 110 & 100 & 91 & 97 & 43 \\
\hline & $X_{z}$ & 107 & 97 & 87 & 76 & 57 & 79 \\
\hline & $P_{z}$ & 93 & 102 & 111 & 119 & 137 & 117 \\
\hline & STE market share & 65.1 & 66.3 & 67.7 & 69.5 & 100 & 31.5 \\
\hline & $M$ market share & 34.9 & 33.7 & 32.3 & 30.5 & 0 & 68.5 \\
\hline \multirow[t]{6}{*}{25} & $X M_{z}$ & 68 & 56 & 0 & 0 & 0 & 0 \\
\hline & $X S_{z}$ & 162 & 152 & 156 & 143 & 130 & 117 \\
\hline & $X_{z}$ & 122 & 112 & 91 & 83 & 76 & 68 \\
\hline & $P_{z}$ & 81 & 89 & 107 & 114 & 120 & 126 \\
\hline & STE market share & 76.9 & 79.0 & 100 & 100 & 100 & 100 \\
\hline & $M$ market share & 23.1 & 21.0 & 0 & 0 & 0 & 0 \\
\hline
\end{tabular}

Note: Typeface: regular, regime $\{2,2\}$; bold, regime $\{3,2\}$; italic, regime $\{0,2\}$; bold italic, regime $\{3,0\}$. 
Table 5. Welfare as a function of transaction costs and the subsidy $s(U=0 ; G=200)$

\begin{tabular}{|c|c|c|c|c|c|c|c|}
\hline \multirow[t]{2}{*}{$s$} & & \multicolumn{6}{|l|}{$t_{z}$} \\
\hline & & 0 & 3 & 5 & 10 & 15 & 20 \\
\hline \multirow[t]{4}{*}{0} & $W_{i}$ & 100 & 76 & 54 & 36 & 135 & 135 \\
\hline & $W_{j}$ & 100 & 80 & 63 & 47 & 0 & 0 \\
\hline & $W_{z}$ & 100 & 80 & 63 & 48 & 40 & 40 \\
\hline & Total welfare & 100 & 79 & 61 & 45 & 47 & 47 \\
\hline \multirow[t]{4}{*}{2} & $W_{i}$ & 94 & 71 & 50 & 32 & 63 & 135 \\
\hline & $W_{j}$ & 103 & 8 & 66 & 50 & 13 & 0 \\
\hline & $W_{z}$ & 104 & 84 & 66 & 50 & 63 & 40 \\
\hline & Total welfare & 101 & 56 & 62 & 46 & 46 & 47 \\
\hline \multirow[t]{4}{*}{4} & $W_{i}$ & 89 & 66 & 46 & 29 & 55 & 79 \\
\hline & $W_{j}$ & 105 & 85 & 67 & 52 & 14 & 5 \\
\hline & $W_{z}$ & 107 & 87 & 69 & 53 & 66 & 57 \\
\hline & Total welfare & 103 & 82 & 64 & 47 & 46 & 44 \\
\hline \multirow[t]{4}{*}{6} & $W_{i}$ & 83 & 61 & 42 & 25 & 0 & 71 \\
\hline & $W_{j}$ & 106 & 86 & 69 & 53 & 60 & 6 \\
\hline & $W_{z}$ & 111 & 90 & 72 & 55 & 28 & 60 \\
\hline & Total welfare & 104 & 83 & 64 & 48 & 33 & 44 \\
\hline \multirow[t]{4}{*}{8} & $W_{i}$ & 78 & 56 & 38 & 22 & 0 & 63 \\
\hline & $W_{j}$ & 107 & 87 & 69 & 53 & 59 & 5 \\
\hline & $W_{z}$ & 115 & 94 & 75 & 58 & 30 & 63 \\
\hline & Total welfare & 104 & 84 & 65 & 49 & 33 & 44 \\
\hline \multirow[t]{4}{*}{25} & $W_{i}$ & 39 & 23 & 0 & 0 & 0 & 0 \\
\hline & $W_{j}$ & 79 & 58 & 66 & 40 & 18 & 0 \\
\hline & $W_{z}$ & 15 & 126 & 82 & 69 & 57 & 46 \\
\hline & Total welfare & 41 & 81 & 60 & 45 & 32 & 21 \\
\hline
\end{tabular}

Note: Typeface: regular, regime $\{2,2\}$; bold, regime $\{3,2\}$; italic, regime $\{0,2\}$; bold italic, regime $\{3,0\}$.

Finally, when transaction costs are above the critical level, eliminating $s$ results in a private-firm monopoly (regime $\{3,0\}$ ). The impact of this policy shock depends on the initial regime, i.e. the size of the subsidy $s$. If initially there is a duopoly (regime $\{3,2\}$ ), then the regime shift implies a reduction in total exports and an increase in price in $z$. Country $i$ is obviously better off, while both countries $j$ and $z$ are worse off. Nevertheless, overall this policy change may be welfare-improving, as the gains of country i's producers and the private firm may be large enough to offset the losses in all the other countries. These findings are different from those predicted when a fixed market structure is assumed and the possibility of vertical integration is ignored. In this model, after subsidy elimination, the STE is no longer competitive vis $\grave{a}$ vis the vertically integrated private firm. This would not 
happen if the private firm as well was assumed to operate as a "pure middleman'. Thus, in this model, there is a huge increase in exports and welfare of country $i$ and a more pronounced decline in the welfare of country $j$, as well as in that of its producers.

If, however, $s$ is initially large enough for a monopoly of the STE to prevail, then subsidy elimination and the consequent shift to a private-firm monopoly may or may not result in an increase in total exports, depending on the initial value of the subsidy. In the example, if $s=6$, then total exports increase

Table 6. Exports, prices and market shares as a function of transaction costs and the subsidy $U(s=0 ; G=200)$

\begin{tabular}{|c|c|c|c|c|c|c|c|}
\hline \multirow[t]{2}{*}{$U$} & & \multicolumn{6}{|l|}{$t_{z}$} \\
\hline & & 0 & 3 & 5 & 10 & 15 & 20 \\
\hline \multirow[t]{6}{*}{0} & $X M_{z}$ & 100 & 89 & 77 & 66 & 152 & 152 \\
\hline & $X S_{z}$ & 100 & 90 & 81 & 71 & 0 & 0 \\
\hline & $X_{z}$ & 100 & 90 & 79 & 69 & 64 & 64 \\
\hline & $P_{z}$ & 100 & 108 & 117 & 126 & 130 & 130 \\
\hline & STE market share & 58.3 & 58.8 & 59.3 & 60.1 & 0 & 0 \\
\hline & $M$ market share & 41.7 & 41.2 & 40.7 & 39.9 & 100 & 100 \\
\hline \multirow[t]{6}{*}{20} & $X M_{z}$ & 100 & 89 & 77 & 66 & 152 & 152 \\
\hline & $X S_{z}$ & 100 & 90 & 81 & 71 & 0 & 0 \\
\hline & $X_{z}$ & 100 & 90 & 79 & 69 & 64 & 64 \\
\hline & $P_{z}$ & 100 & 108 & 117 & 126 & 130 & 130 \\
\hline & STE market share & 58.3 & 58.8 & 59.3 & 60.1 & 0 & 0 \\
\hline & $M$ market share & 41.7 & 41.2 & 40.7 & 39.9 & 100.0 & 100 \\
\hline \multirow[t]{6}{*}{50} & $X M_{z}$ & 100 & 89 & 77 & 66 & 152 & 140 \\
\hline & $X S_{z}$ & 100 & 90 & 81 & 71 & 0 & 23 \\
\hline & $X_{z}$ & 100 & 90 & 79 & 69 & 64 & 72 \\
\hline & $P_{z}$ & 100 & 108 & 117 & 126 & 130 & 123 \\
\hline & STE market share & 58.3 & 58.8 & 59.3 & 60.1 & 0 & 18.7 \\
\hline & $M$ market share & 41.7 & 41.2 & 40.7 & 39.9 & 100.0 & 81.3 \\
\hline \multirow[t]{6}{*}{100} & $X M_{z}$ & 100 & 89 & 77 & 66 & 132 & 140 \\
\hline & $X S_{z}$ & 100 & 90 & 81 & 71 & 38 & 23 \\
\hline & $X_{z}$ & 100 & 90 & 79 & 69 & 100 & 72 \\
\hline & $P_{z}$ & 100 & 108 & 117 & 126 & 118 & 123 \\
\hline & STE market share & 58.3 & 58.8 & 59.3 & 60.1 & 22.4 & 18.7 \\
\hline & $M$ market share & 41.7 & 41.2 & 40.7 & 39.9 & 55.2 & 81.3 \\
\hline \multirow[t]{6}{*}{200} & $X M_{z}$ & 100 & 89 & 77 & 66 & 132 & 140 \\
\hline & $X S_{z}$ & 100 & 90 & 81 & 71 & 38 & 23 \\
\hline & $X_{z}$ & 100 & 90 & 79 & 69 & 100 & 72 \\
\hline & $P_{z}$ & 100 & 108 & 117 & 126 & 118 & 123 \\
\hline & STE market share & 58.3 & 58.8 & 59.3 & 60.1 & 22.4 & 18.7 \\
\hline & $M$ market share & 41.7 & 41.2 & 40.7 & 39.9 & 55.2 & 81.3 \\
\hline
\end{tabular}

Note: Typeface: regular, regime $\{2,2\}$; bold, regime $\{3,2\}$; italic, regime $\{0,2\}$; bold italic, regime $\{3,0\}$. 
because, when transaction costs are high, equilibrium exports of the vertically integrated firm are higher than those of the STE maximising producer welfare; however, if $s$ is very high (in Table 5, $s=25$ ) then STE exports may be higher than those of the vertically integrated firm. In both cases, the gains of country $i$ are very high, and the losses of country $j$ are relevant, despite the large benefits due to eliminating the government expenditure. Overall, this regime shift is welfare-improving.

Tables 6 and 7 report the results of eliminating the subsidy $U$, under the assumption that $s=0$ and for the market structure changes illustrated in Figure 3. As already mentioned in the previous section, when $t_{z}$ is below the critical level, eliminating $U$ has no effect on market structure; furthermore, there are not even any trade and welfare effects. This is because eliminating $U$ does not influence exports of either firm. Rather, it affects only the distribution of welfare within country $j$ : while total welfare of country $j$ does not change, eliminating $U$ shifts the government expenditure previously devoted to the subsidy, from producers back to the taxpayer. The payoff to the STE declines, but as long as it remains positive, this does not produce any other effect.

Table 7. Welfare as a function of transaction costs and the subsidy $U(s=0 ; G=200)$

\begin{tabular}{|c|c|c|c|c|c|c|c|}
\hline \multirow[t]{2}{*}{$U$} & & \multicolumn{6}{|l|}{$t_{z}$} \\
\hline & & 0 & 3 & 5 & 10 & 15 & 20 \\
\hline \multirow[t]{4}{*}{0} & $W_{i}$ & 100 & 76 & 54 & 36 & 135 & 135 \\
\hline & $W_{j}$ & 100 & 80 & 63 & 47 & 0 & 0 \\
\hline & $W_{z}$ & 100 & 80 & 63 & 48 & 40 & 40 \\
\hline & Total welfare & 100 & 79 & 61 & 45 & 47 & 47 \\
\hline \multirow[t]{4}{*}{20} & $W_{i}$ & 100 & 76 & 54 & 36 & 135 & 135 \\
\hline & $W_{j}$ & 100 & 80 & 63 & 47 & 0 & 0 \\
\hline & $W_{z}$ & 100 & 80 & 63 & 48 & 40 & 40 \\
\hline & Total welfare & 100 & 79 & 61 & 45 & 47 & 47 \\
\hline \multirow[t]{4}{*}{50} & $W_{i}$ & 100 & 76 & 54 & 36 & 135 & 95 \\
\hline & $W_{j}$ & 100 & 80 & 63 & 47 & 0 & 2 \\
\hline & $W_{z}$ & 100 & 80 & 63 & 48 & 40 & 52 \\
\hline & Total welfare & 100 & 79 & 61 & 45 & 47 & 44 \\
\hline \multirow[t]{4}{*}{100} & $W_{i}$ & 100 & 76 & 54 & 36 & 70 & 95 \\
\hline & $W_{j}$ & 100 & 80 & 63 & 47 & 11 & 2 \\
\hline & $W_{z}$ & 100 & 80 & 63 & 48 & 60 & 52 \\
\hline & Total welfare & 100 & 79 & 61 & 45 & 46 & 44 \\
\hline \multirow[t]{4}{*}{200} & $W_{i}$ & 100 & 76 & 54 & 36 & 70 & 95 \\
\hline & $W_{j}$ & 100 & 80 & 63 & 47 & 11 & 2 \\
\hline & $W_{z}$ & 100 & 80 & 63 & 48 & 60 & 52 \\
\hline & Total welfare & 100 & 79 & 61 & 45 & 46 & 44 \\
\hline
\end{tabular}

Note: Typeface: regular, regime $\{2,2\}$; bold, regime $\{3,2\}$; italic, regime $\{0,2\}$; bold italic, regime $\{3,0\}$. 
Relevant trade and welfare effects occur if transaction costs are above the critical value and if, after eliminating $U$, the payoff to the STE becomes negative. The regime shift from a duopoly (regime $\{3,2\}$ ) to a monopoly of the private firm (regime $\{3,0\}$ ) implies a decrease in exports and a rise in the price in market $z$. Country $z$ is worse off and even welfare in country $j$ declines. In this example, the increase in country $i$ 's welfare may be so large that even overall welfare improves.

\section{Conclusions}

In order to assess the effects on market structure, trade and welfare of eliminating subsidies to STEs in agricultural markets, as tentatively agreed at the WTO Hong Kong Ministerial in December 2005, a theoretical duopoly model has been developed, where a private trader competes with an STE on a foreign market. Besides the differences in the objective functions, broadly stressed by the literature on agricultural STEs, the model introduces a further distinction between the private trader and the STE, namely their different potential for forward integration. Building on the theory of multinational enterprises and on game theoretical models including multinational firms, the model assumes that the private firm may choose vertical integration in order to eliminate the costly arm's-length transactions; this option is chosen by the private firm when transaction costs are high enough with respect to the fixed costs associated with vertical integration. A further key feature of the model developed in this paper is that market structure is the outcome of the first stage of the game, and hence endogenous.

The paper's most relevant finding is that eliminating STE subsidies may have different impacts on market structure, trade and welfare depending on the initial market structure and the private trader's degree of vertical integration. The paper identifies a variety of possible situations occurring on the third market, under which the elimination of subsidies may produce rather diverse results. Furthermore, it is also emphasised that the impact of eliminating STE subsidies that affect fixed costs is very different from that of eliminating subsidies affecting variable costs; while the latter influence the choices of both firms, and thus always affect exports and welfare, the former influence only the payoff to the STE and, consequently, its entry choice. This means that eliminating fixed cost subsidies may affect market structure, trade and countries' welfare only if before the policy change the STE's disadvantage with respect to the private firm is so large that without subsidies the STE cannot enter the market. In all other cases, eliminating fixed cost subsidies does not produce any change in market structure, trade or countries' welfare.

These findings may have interesting implications for the debate on the expected effects of the WTO agreement on agriculture. The results suggest that the impact of STE subsidy elimination should be assessed on a case-bycase basis, as the effect on market structure, trade and welfare may be very different depending on the conditions occurring on the specific third market. The paper has shown, for example, that the impact is likely to be smaller if, 
for any reason, the private firm on that market is not vertically integrated. In this case, the elimination of subsidies affecting variable costs reduces the STE market share and increases that of the private firm; market structure does not change, even though trade diminishes and overall welfare falls. At the same time, eliminating subsidies affecting the STE's fixed costs does not have trade effects, and only transfers resources domestically from producers back to taxpayers. Conversely, these policy changes may affect market structure in markets where private firms are vertically integrated; in this case, it is possible that subsidy elimination will make the STE payoff negative, and this will have drastic negative effects on the welfare of the country whose exports are managed by the STE.

These implications overall reinforce the already well-established idea that the STE issue should be addressed within the WTO framework on a case-by-case basis, as the trade-distorting impact of STEs depends upon their nature and their objectives (e.g. Dixit and Josling, 1997; OECD, 2001; McCorriston and MacLaren, 2002). This paper adds a further perspective to the discussion of this issue, by stressing that another factor influencing the impact of any further disciplining of STEs that needs to be taken into account is the degree of integration of their rivals and the existing market structure. The more integrated private traders are, the greater their advantages and the higher the probability that eliminating government-granted STE privileges may lead to a negative payoff to the STE. In the model presented in this paper, this causes the STE to exit from the export market, competition is reduced and producers in the country whose exports are managed by the STE become significantly worse off. In this perspective, concerns that eliminating STE privileges may end up increasing the market power of large private traders are justified (Fulton et al., 2001; Young, 2005). One possible policy implication is that the removal of STE subsidies, which certainly alter competition with private traders, should be accompanied by domestic reforms removing existing restrictions to STE operations and re-establishing 'fair' competition between the exporting firms. Because producers in countries where STEs are active are penalised by the structural disadvantage of the STEs relative to private firms, the possibility for STEs to purchase facilities, to invest abroad in trading assets and to vertically integrate could be introduced. Such a process, along with the privatisation of previously state-owned enterprises, has already begun in some STEs, such as the former New Zealand Dairy Board and the Australian Wheat Board (Lobb and Fraser, 2005).

On the contrary, when conditions on the third market are such that the private firms are not vertically integrated, then privileges to exporting STEs provide them with a competitive advantage with respect to private traders and the removal of the subsidies may lead to increased competition, trade and welfare. Again, positions taken in this respect by some WTO members are, therefore, justified.

These implications emphasise the potential importance of taking market structure issues into consideration in multilateral trade negotiations. The level of competition in international markets to date is not an issue in the 
WTO, as no agreement was reached at the Cancun Ministerial, when this possibility was debated, to include 'trade and competition' among the negotiable issues in the DDA round. As a result, competition policy for WTO remains a matter for national governments. However, trade policies issues are closely linked to market structure and competition issues (MacLaren and Josling, 1999). The need for explicit consideration of the issues of market structure and competition when dealing with further STE disciplines in WTO negotiations is an additional implication of the analysis developed in this paper.

\section{Acknowledgements}

I wish to thank Giovanni Anania and three anonymous referees for their useful comments on an earlier draft of the paper. Financial support received by the Italian Ministry for University and Scientific and Technological Research is gratefully acknowledged (Research Program of National Scientific Relevance 'Doha Development Agenda - Research Network'; Research Unit: Dipartimento di Istituzioni Economiche e Finanziarie, Università di Macerata).

\section{References}

Abbott, P. and Young, Y. (2004). Export competition issues in the Doha Round. In G. Anania, M. Bohman, C. Carter, and A. McCalla (eds), Agricultural Policy Reform and the WTO: Where Are We Heading? Cheltenham: Edward Elgar, 252-283.

Alston, J. M. and Gray, R. (2000). State trading versus export subsidies: the case of Canadian wheat. Journal of Agricultural and Resource Economics 25: 51-67.

Brooks, H. G. and Schmitz, T. (1999). Price discrimination in the international grain trade: the case of the Canadian Wheat Board feed barley exports. Agribusiness: An International Journal 15: 313-322.

Carter, C. A., Loyns, R. M. A. and Berwald, D. (1998). Domestic costs of statutory marketing authorities: the case of the Canadian Wheat Board. American Journal of Agricultural Economics 80: 313-324.

Carter, C. A. and Wilson, W. (1997). Emerging differences in state grain trading: Australia and Canada. Agricultural Economics 16: 87-98.

Caves, R. (1977). Organization, scale and performance of the grain trade. Food Research Institute Studies 14: 107-123.

Caves, R. (1996). Multinational Enterprise and Economic Analysis, (2nd edition). Cambridge: Cambridge University Press.

Chalmin, P. (1986). The strategy of a multinational in the world sugar economy. The case of Tate and Lyle, 1870-1980. In A. Teichova, M. Levy-Leboyer, and H. Nussbaum, (eds), Multinational Enterprise in Historical Perspective. Cambridge: Cambridge University Press, 103-115.

Davies, S. (1986). The grain trading companies. In N. Butler (ed), International Grain Trade. London: Croom Helm, 90-112. 
Dixit, P. and Josling, T. (1997). State trading in agriculture: an analytical framework. Working paper 97-4. International Agricultural Trade Research Consortium.

Dong, F., Marsh, T. and Stiegert, K. (2006). State trading enteprises in a differentiated product environment: the case of global malting barley markets. American Journal of Agricultural Economics 88: 90-103.

Fulton, M., Larue, B. and Veeman, M. (2001). The impact of export state trading enterprises under imperfect competition: the small country case. Canadian Journal of Agricultural Economics 47: 363-373.

Furtan, W. H. (2005). Transformative change in agriculture: the Canadian Wheat Board. The Estey Centre Journal of International Law and Trade Policy 6: 95-107.

Goodloe, C. (2004). The Canadian Wheat Board: government guarantees and hidden subsidies? The Estey Centre Journal of International Law and Trade Policy 5: 102-122.

Hamilton, S. F. and Stiegert, K. W. (2000). Vertical co-ordination, antitrust law, and international trade. Journal of Law and Economics 43: 143-156.

Hamilton, S. F. and Stiegert, K. W. (2002). An empirical test of the rent-shifting hypothesis: the case of state trading enterprises. Journal of International Economics 58: 135-157.

Hayenga, M. and Wilsner, R. (2000). Cargill's acquisition of continental Grain's grain merchandising business. Review of Agricultural Economics 22: 252-266.

Horstmann, I. J. and Markusen, J. R. (1992). Endogenous market structures in international trade. Journal of International Economics 32: 109-129.

Kneen, B. (2002). Invisible Giant. Cargill and its Transnational Strategies. London: Pluto Press.

Lavoie, N. (2005). Price discrimination in the context of vertical differentiation: an application to Canadian wheat exports. American Journal of Agricultural Economics 87: $835-854$.

Lobb, A. E. and Fraser, R. W. (2005). Implications of recently Australian wheat industry developments for domestic and overseas prices. Journal of International Agricultural Trade and Development 1: 93-108.

MacLaren, D. and Josling, T. (1999). Competition policy and international agricultural trade. working paper 99-7. International Agricultural Trade Research Consortium.

Markusen, J. R. (2002). Multinational Firms and the Theory of International Trade. Cambridge, MA: The MIT Press.

McCorriston, S. and MacLaren, D. (2002). Perspectives on the state trading issue in the WTO negotiations. European Review of Agricultural Economics 29: 131-154.

McCorriston, S. and MacLaren, D. (2005). Single-desk state trading exporters. European Journal of Political Economy 21: 503-524.

McCorriston, S. and MacLaren, D. (2007). Do state trading exporters distort trade? European Economy Review 51: 225-246.

Motta, M. (1992). Multinational firms and tariff-jumping. European Economy Review 36: $1557-1571$.

OECD (2001). State Trading Enterprises in Agriculture. Paris: OECD.

Read, R. A. (1986). The banana industry. In M. C. Casson (ed), Multinationals and World Trade. Vertical Integration and the Division of Labour in World Industries. London: Allen \& Unwin. 
Scoppola, M. (2007). Economies of scale and market structure in international grain trade. Agricultural Economics 37: 277-291.

Spencer, B. J. (2005). International outsourcing and incomplete contracts. Working paper 11418. Cambridge, MA: National Bureau of Economic Research.

Thursby, M. (1988). Strategic models, markets structure and state trading: an application to agriculture. In R. Baldwin (ed) Trade Policy Issue and Empirical Analysis. Chicago: The University of Chicago Press, 79-105.

Wilson, W. W. and Dahl, B. L. (1999). Transnational grain firms: evolution and strategies in North America. Agricultural Economics Report no. 412. Fargo, ND: North Dakota State University.

WTO (2000a). Proposal for Comprehensive Long-Term Agricultural Trade ReformSubmission from the United States. WTO G/AG/NG/W/15. Geneva: WTO.

WTO (2000b). EC Comprehensive Negotiating Proposal. G/AG/NG/W/90. Geneva: WTO.

WTO (2001a). State trading Enterprises. Proposal by Argentina, Brazil, Paraguay and Uruguay (MERCOSUR), Chile and Colombia. G/AG/NG/W/107. Geneva: WTO.

WTO (2001b). Statements by Australia. G/AG/NG/W/166. Geneva: WTO.

Young, L. M. (2005). Export competition disciplines in the Doha Round. Trade Policy Issues Paper 3. International Agricultural Trade Research Consortium. 
Table A1. Exports and domestic sales under the different outcomes of the game

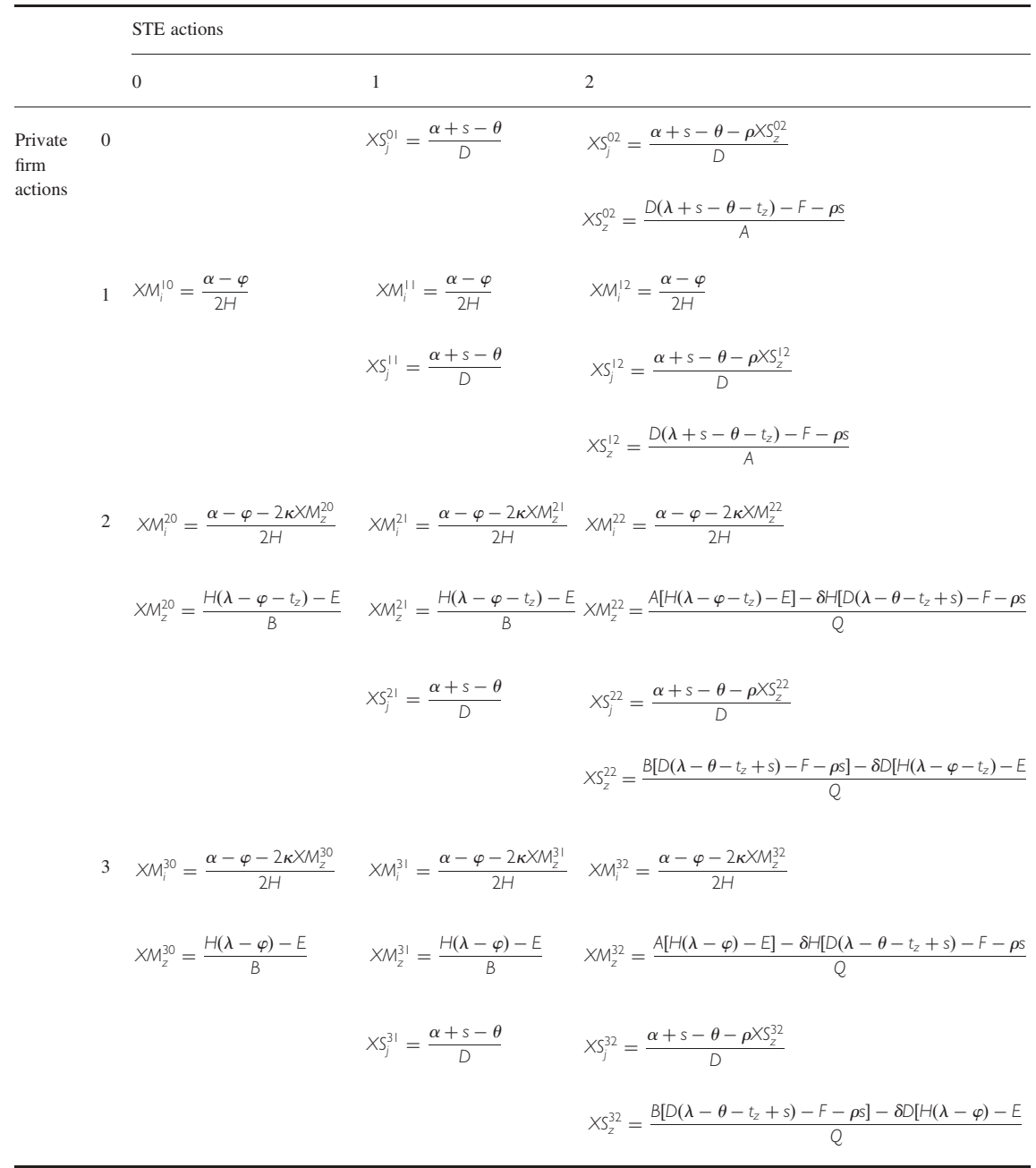


Table A2. Payoff to the firms under the different outcomes of the game

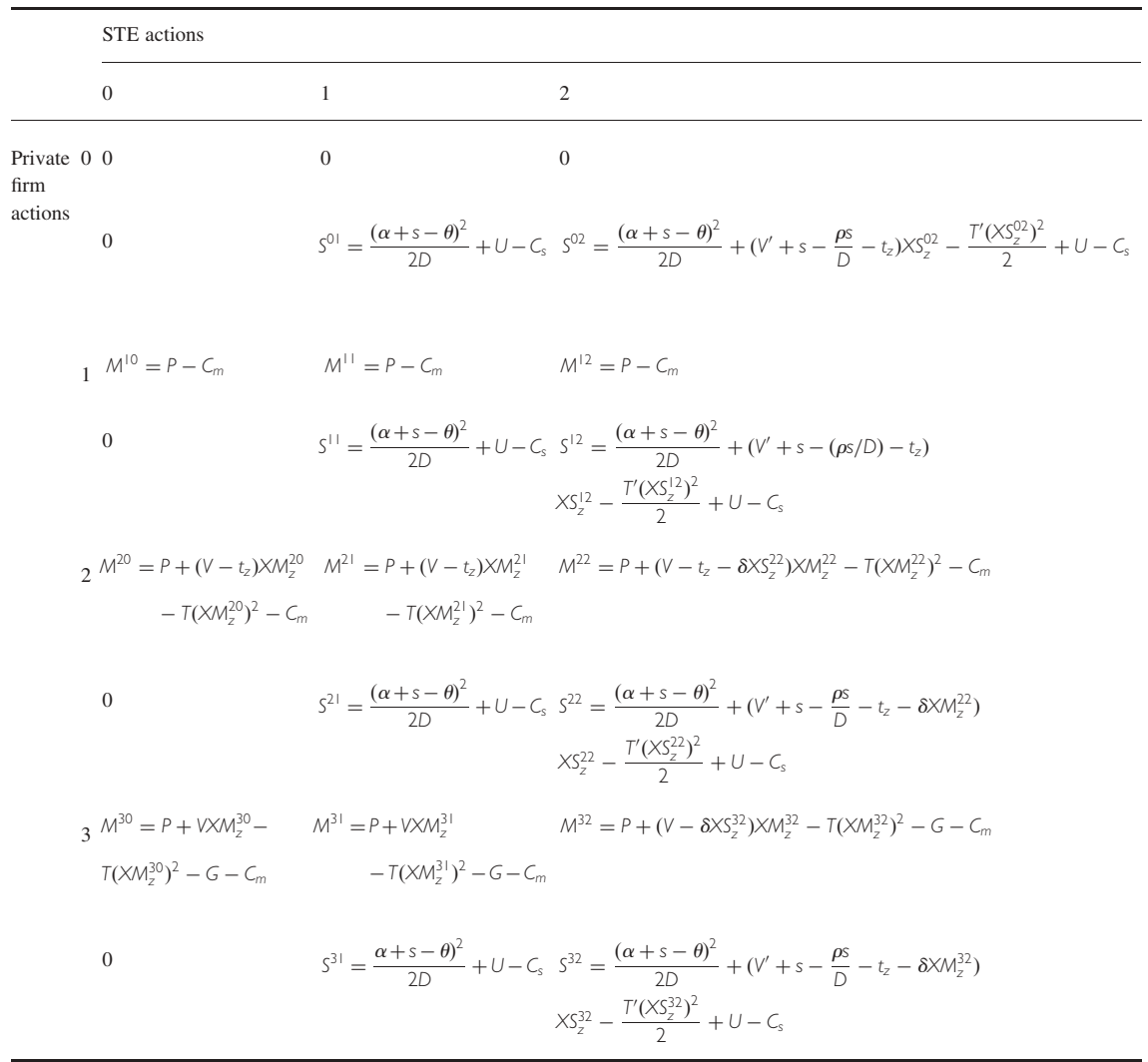

Note: $P=\frac{(\alpha-\varphi)^{2}}{4 H}, \quad V=\lambda-\varphi-\frac{E}{H}, \quad T=\delta+\kappa-\frac{\kappa^{2}}{H}, V^{\prime}=\lambda-\theta-\frac{F}{D}, T^{\prime}=2 \delta+\rho-\frac{\rho^{2}}{D}$.

Corresponding author: Margherita Scoppola, Dipartimento di Studi sullo Sviluppo Economico, University of Macerata, Piazza Oberdan 3, 62100 Macerata, Italy. E-mail: scoppola@unimc.it 